\title{
Perception of the Controllability Principle and its Consequences for Budgetary Control
}

Ryota Machida* and Tomoki Oshika

Faculty of Commerce, Waseda University, Japan

\begin{abstract}
In this study, we empirically examined the following three relationships through quantitative analysis of web-based survey data collected from managers of Japanese firms. First, we examined the relationship between managers' perceptions of controllability and budget use. Second, we examined the relationship between budget use and altruistic behavior. Third, based on managers' perceptions of controllability, we examined the relationship between altruistic behavior and managerial performance. Structural equation modeling revealed that not only did perception of low controllability by managers promoted the use of budgeting, it also promoted organizational citizenship behavior through increased trust in superiors, which subsequently enhanced managerial performance.
\end{abstract}

Keywords: managerial perception, controllability principle, altruistic behavior, organizational citizenship behavior, trust, managerial performance

\section{$\underline{\text { ARTICLE INFO }}$}

\section{Article History:}

Received: 19 June 2021

Accepted: 2 November 2021

Published: 1 December 2021

* Corresponding author: Ryota Machida. Email: r-machida@aoni.waseda.jp 


\section{INTRODUCTION}

The controllability principle has long held a significant role in the context of responsibility accounting (Banker \& Datar, 1989; Demski, 1994; Moers, 2006; Solomons, 1965). This principle reflects the idea that "authority and responsibility should be matched" as a social norm that stems from appropriate self-awareness of the role of individuals and organizations, as well as the legitimacy and fairness of performance evaluations (Simons, 2010). A lack of controllability has managers increased role stress, reduced their performance, which can lead to dysfunctional behavior (Burkert et al., 2011; Su et al., 2021).

In empirical management accounting research, how responsibility accounting and management accounting tools work as a management control system (hereafter, MCS) is not fully understood. Although some cases of innovative MCS have addressed the importance of less controllable performance measures (Frow et al., 2005; Henttu-Aho, 2018; Simons \& Dávila, 2021), the role of the controllability principle is not comprehensively understood (Burkert et al., 2017; Dent, 1987; Fremgen \& Liao, 1981; Giraud et al., 2008; Merchant, 1989; Vancil, 1979). Besides, a recent study shows that interactive use of MCS motivates managers not only to identify opportunities for the emergence of strategies through dialogue, but also to enhance altruistic behavior (Matsuo et al., 2021).

In addition, it is said that the relationship between authority and responsibility is extremely unclear among Japanese individuals and organizations. This claim is often made in comparison to western countries in which individuals and jobs are clearly defined, based on a written contract such as a job description (Tanaka, 2012), but the claim is not supported by clear evidence.

In this study, we clarified the following three relationships through a quantitative analysis of data collected via an Internet-based survey of managers at Japanese firms. First, we examined the relationship between managers' perceptions of the controllability principle and the use of budget. Second, we examined the relationship between the use of budget and altruistic behavior. Third, in the context of managers' perception of the controllability principle, we examined the relationship between altruistic behavior and their managerial performance. 
The article proceeds as follows. Section 2 provides a literature review discussing prior research, defining the research question, and constructing hypotheses. Section 3 details the research design. Section 4 reports our results, and Section 5 provides our discussion. Section 6 discusses the contributions of the study, its limitations, and future research challenges.

\section{LITERATURE REVIEW AND HYPOTHESES DEVELOPMENT}

\section{The Controllability Principle and its Consequences}

Responsibility accounting is based on the controllability principle, which consists of measurement/evaluation using items that can be controlled by an individual or organization. For example, performance evaluations of the operations department and its head, based on direct cost accounting, is dependent on evaluation only using items that can be controlled by the head of the division, and the division itself (Solomons, 1965). This theory also posits that application of the controllability principle exerts a positive influence on individual and organizational outcomes. Burkert et al. (2011) examined the relationship between application of the controllability principle, managers' self-perception of their roles, and outcomes, based on role theory. The results showed that application of the controllability principle indirectly exerted a positive influence on outcomes by reducing role conflict. Adachi (2008) investigated the development of accounting responsibility via Management by Objectives (MBO) in the case of a textile manufacturing company. In the company, management by objectives was used to cultivate a sense of responsibility in individual employees for company objectives, which encouraged participation in the objective setting process, as well as full implementation of responsibility accounting.

While there has been a long-standing argument that full application of the controllability principle is unrealistic (Welsch, 1957; Horngren, 1967), many empirical studies have indicated situations in which the controllability principle was effectively implemented (Bushman et al., 1995; Drury et al., 2005; Fremgen \& Liao, 1981; Merchant, 1989; Moon and Fitzgerald, 1996; Otley, 1990; Rowe et al., 2008; Vancil, 1979). Mixed research by Giraud et al. (2008) showed that managers do not necessarily want to 
apply the controllability principle completely and that there are cases in which they prefer subjective adjustment (neutralization), depending on the uncontrollable factors in play. They preferred not to apply the principle for external uncontrollable factors (external environment) due to its subjective nature and the lack of fairness. However, they were more likely to apply the principle to internal uncontrollable factors (horizontal and vertical mutual dependence).

Studies dating back to the 1980s have described intentional breaches of the controllability principle by individuals and organizations (Dent, 1987; Frow et al., 2005). In the Japanese style of management accounting as represented by amoeba management, responsibility accounting (which is not based on the controllability principle) has been widely discussed. Using the structure of production lines' profit and loss statements, Maruta (2010) showed that amoeba management is not responsibility accounting based on the controllability principle, but instead a collective culture based on the non-equivalency of the gift exchange relationship known as the reciprocity principle. Moreover, in Japanese style management accounting, empowering front-line employees and their interactions are emphasized (Maruta, 2008; Shimizu, 2013). It assumed that intentional breaches of the controllability principle often occur in Japanese management accounting practices.

How does responsibility accounting, which is not based on the controllability principle, effectively function as MCS? Yokota (1998) proposed that the meaning of information provided by MCS should be understood in the context of the system (psychological context), and that contextual information determines individual attitudes. The effect of responsibility accounting according to this proposition is that "shared responsibility becomes contextual information, the meaning and use of management accounting information are defined, and action which benefits the organization as a whole is encouraged" (Simons, 2005). Here, shared responsibility means "the obligation to think it is natural to help others working for the shared objective" (Simons, 2005). Simons identified a shared objective, a sense of belonging to the group, trust, and fairness as conditions for sharing responsibility. The mechanism by which shared responsibility works is as follows: when the organization's objective and mission are felt strongly and shared, "people in the organization as a whole commit to helping each other" and the responsibility for achieving the mission is 
shared. Employees with a heightened sense of belonging to the organization will help group members. Trust among employees engenders a firm belief that if one actively supports other group members, this will be paid back to oneself, and behavior to voluntarily and actively help others achieve the shared objective is encouraged by fairness in performance evaluations and rewards (Simons, 2005). Desirable behavior of the employee in this case thus consists of supportive behavior toward others.

Despite the topic being central to management accounting research, few empirical studies have focused on the controllability principle and its consequences. More recently, Simons and Dávila (2021) presented a long-term field study as evidence for how purposeful violations of the controllability principle in the context of strategic change support desirable consequences for organizations. Some studies provide largescale evidence. Burkert et al. (2011) found that applying the controllability principle mitigates managers' role stress, resulting in a positive effect on their performance. As an alternative explanation, Burkert et al. (2017) proposed that lack of controllability stimulates flexible role orientations, resulting in higher levels of proactive work behavior. While these studies suggest different mechanisms underlying the controllability principle, some contextual factors may also be important, such as specific management accounting practices (Burkert et al., 2011).

To address these research gaps, we examined the relationships among controllability, budget use, trust, organizational citizenship behavior, and managerial performance to clarify the effects of Japanese-style responsibility accounting, which is not based on the controllability principle. The study of budget use in the context of shared responsibility based on the work of Simons (2005) has focused on empirical studies of the effects of innovation and interactive control (Abernethy \& Brownell, 1999; Bisbe \& Otley, 2004; Henri, 2006). We focused on how budgets are used because budgetary control is a widely and generally used management accounting tool, and many prior studies of controllability have been carried out in the context of budgetary control (Burkert et al., 2011; Frow et al., 2005). 


\section{Hypotheses Development}

Burkert et al. (2011; 2017) previously created two sub-scales pertaining to application of the controllability principle that assess the sensitivity and precision of the performance measure. These sub-scales have been identified as defining the controllability principle in many prior studies (e.g., Banker \& Datar, 1989; Demski, 1994; Moers, 2006). However, if the perception of controllability as defined by these scales increases, we suggest that the tendency to pay attention to one's performance measures will also increase, which may obstruct altruistic behavior.

Conceptual studies beyond budgeting have recommended prompt feedback based on predictions as well as intentionally breaching the controllability principle (Bogsnes, 2009). This suggests that managers who perceive low controllability may be able to clarify their own actions by increasing the diagnostic use of the budget.

Prior studies that described intentional breaches of the controllability principle have emphasized that low controllability encourages teamwork, cross-sectional activities, and mutual interdependence (Dent, 1987; Frow et al., 2005). These studies indicated that when a manager perceives uncontrollability, an action plan can be developed by using the budget interactively and engaging in discussion with others. Therefore, we proposed:

$\mathbf{H}_{\mathbf{1}}$ : Managers' perceptions of the controllability principle are negatively associated with organizational citizenship behavior.

$\mathbf{H}_{2 \mathrm{a}}$ : Managers' perceptions of the controllability principle are negatively associated with diagnostic use of the budget.

$\mathbf{H}_{2 \mathbf{b}}$ : Managers' perceptions of the controllability principle are negatively associated with interactive use of the budget.

Many prior studies have concluded that diagnostic use of MCS exerts a negative influence on organizational ability and outcomes (e.g., Henri, 2006; Malina \& Selto, 2001). This is because diagnostic use is focused on the execution of existing strategies. These studies raised the possibility of obstructing action to explore opportunities inside and outside the organization, such as innovation and collaboration. 
According to Chong and Mahama (2014), diagnostic use of the budget exerts a positive influence on the collective sense of effectiveness. Due to the diagnostic use, desirable outcomes are shared, and areas in which members would co-operate are identified. However, if emphasis is placed on the monitoring of budgeting management's performance and feedback, it is expected that opportunistic behavior would be encouraged and that one's actions would be restricted to controllable areas.

Cheng and Coyte (2014) demonstrated that interactive use of a strategy map encouraged extra-role behavior (i.e., organizational citizenship behavior) under a subjective weighting incentive scheme. They also reported that use of interactive MCS exerted a positive influence on entrepreneurship and a collective sense of effectiveness (Henri, 2006; Chong \& Mahama, 2014). If the budget is used for discussion and exploration for the organization, regardless of specific roles, it is likely that supportive behavior towards others would be encouraged. Consequently, we hypothesized the following:

$\mathbf{H}_{3 \mathbf{a}}$ : Diagnostic use of the budget is negatively associated with organizational citizenship behavior.

$\mathbf{H}_{3 \mathbf{b}}$ : Interactive use of the budget is positively associated with organizational citizenship behavior.

There are two dimensions to trust: one strengthens the relationship and the other expands it (Yamagishi, 1998). Ohura (2006) proposed that trust restrains opportunistic behavior and encourages information sharing and collaboration among suppliers. Burkert et al. (2011) also showed that trust moderates the influence exerted by role ambiguity and role conflict on outcomes. Therefore, it is highly likely that interactive use of the budget enhances trust in superiors and encourages greater organizational citizenship behavior by strengthening the effects of discussion and exploratory behavior within the organization.

According to a meta-analysis, organizational citizenship behavior exerts a positive influence on all dimensions of performance (Eatough et al., 2011; Organ et al., 2006; Podsakoff et al., 2009). It is assumed that organizational citizenship behavior improves managerial performance. Therefore, we proposed: 
$\mathbf{H}_{4}$ : The relationship between the degree of interactive use of the budget and organizational citizenship behavior is mediated by trust in superiors.

$\mathbf{H}_{5}$ : Organizational citizenship behavior is positively associated with managerial performance.

\section{RESEARCH DESIGN}

\section{Sample Selection, Survey Design, and Measurement}

To test these hypotheses using geographically unbiased samples, we used a web-based survey for data collection. The survey was conducted in June 2018 by a market research firm (Cross Marketing Inc.). The respondents were randomly selected from a database owned by Cross Marketing Inc. All respondents were currently managers in Japanese companies. Our effective sample contained 1,000 of a total of 1,089 returned responses after excluding inappropriate surveys on the basis of screen transition time, trends in answers, and so forth. Following Burkert et al. (2011), Table 1 shows descriptive statistics of the age and gender of the sample.

Table 1: Descriptive Statistics of the Sample

\begin{tabular}{llcc}
\hline \multirow{2}{*}{ Descriptive } & $\begin{array}{c}\text { Total }(\mathbf{N}=\mathbf{1 , 0 0 0}) \\
\text { Frequency }\end{array}$ & Percentage \\
\hline \multirow{2}{*}{ Gender } & Male & 933 & 93.3 \\
& Female & 67 & 6.7 \\
Age & Less than 29 years & 2 & 0.2 \\
min: 27 & 30 years to 35 years & 20 & 2.0 \\
max: 69 & 36 years to 40 years & 60 & 6.0 \\
mean: 51.12 & 41 years to 45 years & 142 & 14.2 \\
& 46 years to 50 years & 196 & 19.6 \\
& 46 years to 50 years & 296 & 29.6 \\
& 55 years and above & 284 & 28.4 \\
\hline
\end{tabular}

To ensure the validity of the survey, a questionnaire was developed based on the following process. First, to ensure the content validity of the questionnaire, back-translation of existing scales was used to make items more understandable for respondents. This process was supported by a Japanese translator, who had earned a bachelor's degree in psychology from 
a university in the U.K. and who is a long-term resident of English-speaking countries. Second, words and expressions in the questionnaire were modified based on feedback from three management accounting researchers and two practitioners concerning focus and clarity.

The survey instruments used in this study were as follows. All variables except class were measured on a 5-point Likert-scale, from 1 (strongly disagree) to 5 (strongly agree). Managers' perceptions of the controllability principle $(\mathrm{CP})$ were measured using the MIMIC (multiple indicators and multiple causes) model developed by Burkert et al. (2011). Both sensitivity (SEN: the extent to which managers' actions can change the result of performance measures) and precision of performance measures (PRE: the extent of noise or deviation in the KPIs) have been used as determinants of the controllability principle in prior research (Banker \& Datar, 1989; Demski, 1994; Moers, 2006). It was assumed that the model would be suitable for the context of this research, as managers' perceptions of the controllability principle affect the extent of budget use. To consider the effects of managerial position on the perception of controllability, positions were coded as an ordinal variable, with (1) vice presidents of divisions as top managers; (2) division managers, section managers, branch/shop managers, and line managers as middle managers; and (3) team managers as lower managers.

Diagnostic (DIAG) and interactive (INTR) use of the budget were measured based on the constructs of Chong and Mahama (2014). These constructs were developed after adding reasons for budget use to the construct created by Henri (2006), based on the use of performance measurement systems. Diagnostic use of the budget was measured using 4 items related to measurement, monitoring, and feedback of performance. Interactive use of the budget was measured via 7 items related to conversation or discussion, attention-seeking, and coherence of organization.

Williams and Anderson's (1991) items were used to measure organizational citizenship behavior (OCB). They considered OCB as consisting of three dimensions, namely in-role behavior (IRB), OCB for Individual (OCB-I), and OCB for organizations (OCB-O). While some studies have suggested that IRB should not be included in the construct of OCB (Podsakoff et al., 1993), Williams and Anderson's (1991) construct had utility in the current study for two reasons. First, this study considered 
how budget use affects managers' behavior, including their behavior in their own role. Second, previous management accounting studies have used this construct (e.g., Cheng \& Coyte, 2014). We examined and displayed the relationship among these three dimensions and other variables in the data analysis section.

Trust (TRU) was measured by four items developed by Read (1962). This construct is often used in management accounting research, such as Burkert et al. (2011) and Lau and Tan (2012), who considered the relationship between an employee's job tension and trust of their superior. An example item is "If my superior makes a decision which seems to be against my interests, I still trust that my superior's decision is justified for other considerations."

Managerial performance (MP) is defined as self-rating of managers' job performance, which includes planning, investigating, and coordinating. We used the constructs of Mahoney et al. (1963, 1965), which have been frequently applied in prior management accounting studies (e.g., Marginson \& Ogden, 2005).

Table 2: Descriptive Statistics of Variables

\begin{tabular}{lcccccc}
\hline Variables & Items & Mean & SD & Min & Max & $\boldsymbol{\alpha}$ \\
\hline PRE & 4 & 2.9 & 0.83 & 1 & 5 & 0.92 \\
SEN & 4 & 3.2 & 0.86 & 1 & 5 & 0.93 \\
CP & 3 & 2.8 & 0.89 & 1 & 5 & 0.91 \\
DIAG & 4 & 3.3 & 1.20 & 1 & 5 & 0.96 \\
INTR & 7 & 3.1 & 1.10 & 1 & 5 & 0.97 \\
IRB & $5(7)^{*}$ & 3.6 & 0.74 & 1 & 5 & 0.92 \\
OCB-I & 7 & 3.3 & 0.68 & 1 & 5 & 0.88 \\
OCB-O & $5(7)^{*}$ & 3.7 & 0.65 & 1 & 5 & 0.79 \\
TRU & 4 & 3.1 & 0.81 & 1 & 5 & 0.90 \\
MP & 9 & 3.2 & 0.62 & 1 & 5 & 0.93 \\
\hline
\end{tabular}

PRE: Precision of performance measures, SEN: Sensitivity of performance measures, CP: Managers' perception of controllability principle, DIAG: Diagnostic use of budget, INTR: Interactive use of budget, IRB: In-role behavior, OCB-I: OCB for individual, OCB-O: OCB for organizations, TRU: Trust, MP: Managerial performance.

* Original question item in brackets. This shows result of five items, excluding items with small factor loadings.

To assess the validity of constructs, confirmatory factor analysis (CFA) was used. As shown in Table 2 the reliability of the constructs was satisfactory, as Cronbach's alpha values largely exceeded 0.8 for almost all 
constructs. In addition, we also checked the validity of the constructs from the following perspectives (Bedford \& Specklé, 2018). First, regarding convergent validity, the unidimensionality of all constructs was confirmed by the CFA because all question items used in the study were developed and tested in prior studies. Thus, we judged convergent validity to be sufficient. Second, discriminant validity was examined by inspecting the confidence interval of correlation coefficients, and the relationship between the square root of AVE (average variance extracted) and the absolute value of correlation coefficients. None of the item's 95\% confidence intervals contained \pm 1 . Next, we confirmed that the square root of AVE was larger than the absolute value of the correlation coefficient between two latent variables. Thus, we established that construct validity was sufficient.

\section{Analytical Method}

Figure 1 shows the theoretical framework of this study. We examined the hypotheses via structural equation modeling (maximum likelihood estimation). Regarding managers' perceptions of the controllability principle and its consequences, we examined three relationships. First, we tested the relationship between the managers' perception of the controllability principle (CP) and their use of the budget (DIAG/INTR), and subsequently assessed the relationship between $\mathrm{CP}$ and OCB. Second, we tested the relationship between use of the budget (DIAG/INTR) and OCB and assessed how trust (TRU) enhanced the relationship between the degree of interactive use of budget (INTR) and OCB. Third, we tested the relationship between OCB and managerial performance (MP).

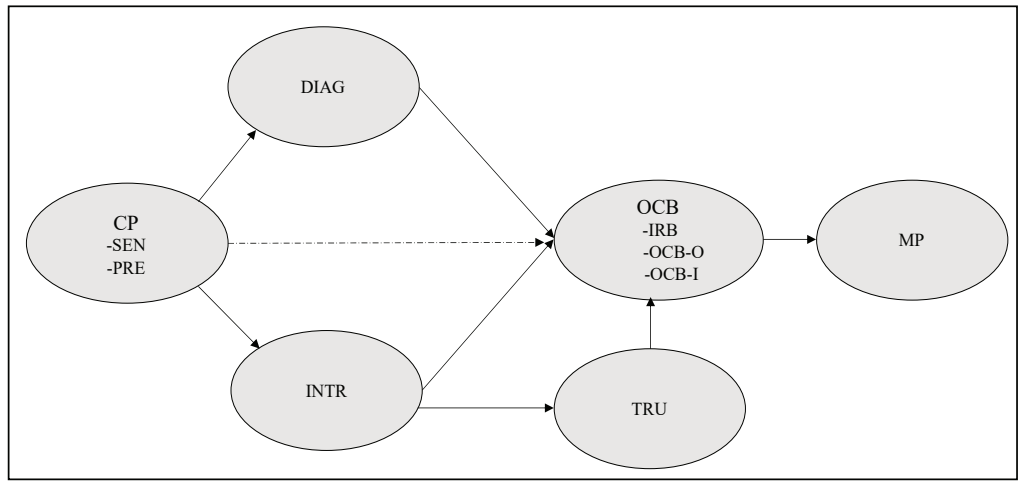

Figure 1: Theoretical Framework of this Study 


\section{EMPIRICAL RESULTS}

The SEM results and goodness-of-fit of the model are shown in Table 3. While some goodness-of-fit indicators were not sufficient due to the complexity of the model, the values of Holter's critical sample index (cn_01 and cn_05) and RMSEA were satisfactory. In this study, the significance level was set at $5 \%$.

Table 3: SEM Results for the Model Test

\begin{tabular}{|c|c|c|c|c|c|c|}
\hline Dep. var & Ind. var & Estimates & Std. Estimates & $p$ value & $R^{2}$ & Sig. \\
\hline \multirow[t]{3}{*}{$\mathrm{CP}$} & SEN & 0.065 & 0.064 & 0.122 & 0.126 & \\
\hline & PRE & -0.374 & -0.386 & 0.000 & & *** \\
\hline & Class & -0.040 & -0.03 & 0.342 & & \\
\hline \multirow[t]{2}{*}{ DIAG } & $\mathrm{CP}$ & -0.484 & -0.317 & 0.000 & 0.167 & $* * *$ \\
\hline & Class & -0.554 & -0.268 & 0.000 & & $* * *$ \\
\hline \multirow[t]{2}{*}{ INTR } & $\mathrm{CP}$ & -0.408 & -0.318 & 0.000 & 0.168 & *** \\
\hline & Class & -0.462 & -0.267 & 0.000 & & $* * *$ \\
\hline \multirow[t]{3}{*}{ TRUST } & DIAG & -0.028 & -0.045 & 0.186 & 0.128 & \\
\hline & INTR & 0.274 & 0.365 & 0.000 & & *** \\
\hline & $\mathrm{CP}$ & 0.011 & 0.011 & 0.756 & & \\
\hline \multirow[t]{4}{*}{ IRB } & TRUST & 0.430 & 0.422 & 0.000 & 0.207 & $* * *$ \\
\hline & DIAG & 0.035 & 0.054 & 0.093 & & * \\
\hline & INTR & -0.011 & -0.014 & 0.687 & & \\
\hline & $\mathrm{CP}$ & -0.128 & -0.131 & 0.000 & & $* * *$ \\
\hline \multirow[t]{4}{*}{ OCB-I } & TRUST & 0.350 & 0.419 & 0.000 & 0.290 & *** \\
\hline & DIAG & 0.002 & 0.004 & 0.899 & & \\
\hline & INTR & 0.095 & 0.152 & 0.000 & & *** \\
\hline & $\mathrm{CP}$ & -0.118 & -0.147 & 0.000 & & $* * *$ \\
\hline \multirow[t]{4}{*}{ OCB-O } & TRUST & 0.374 & 0.382 & 0.000 & 0.224 & $* * *$ \\
\hline & DIAG & 0.055 & 0.089 & 0.007 & & $* *$ \\
\hline & INTR & -0.046 & -0.062 & 0.077 & & \\
\hline & $\mathrm{CP}$ & -0.237 & -0.252 & 0.000 & & $* * *$ \\
\hline \multirow[t]{3}{*}{ MP } & IRB & 0.325 & 0.437 & 0.000 & 0.350 & $* * *$ \\
\hline & OCB-I & 0.265 & 0.293 & 0.000 & & *** \\
\hline & OCB-O & 0.027 & 0.035 & 0.247 & & \\
\hline
\end{tabular}

${ }^{* * *} p<0.001,{ }^{* *} p<0.01,{ }^{*} p<0.05$.
Goodness-of-fit of the model: $\mathrm{X}^{2}=7632.927, d f=1622, p<.01, \mathrm{CFI}=0.881, \mathrm{TLI}=0.875, \mathrm{RMSEA}=0.061, \mathrm{cn} 05=$ $225.921, \mathrm{cn} \_01=231.244, \mathrm{GFI}=0.778, \mathrm{AGFI}=0.758$.

Controllability exerted a negative influence on all lower dimensions of organizational citizenship behavior (In-role behavior: -0.128, $p<0.001$; OCB-I: $-0.118, p<0.001$; OCB-O: $-0.237, p<0.001)$. That is, higher 
controllability obstructed organizational citizenship behavior. Therefore, H1 was supported.

Controllability also exerted a negative influence on diagnostic use of the budget $(-0.484, p<0.001)$. that is, when controllability decreased, diagnostic use of the budget was encouraged. Therefore, H2a was also supported. Furthermore, controllability also exerted a negative influence $(-0.408, p<0.001)$ on interactive use of the budget. Consequently, H2b was similarly supported.

H3a was not supported. While OCB-O $(0.055, p<0.01)$ was significant, the estimate value was small and positive. These results contradicted our prediction. The results imply that when the budget was used diagnostically, organizational citizenship behavior was slightly encouraged. $\mathrm{H} 3 \mathrm{~b}$ was this partially supported, given that only OCB-I was statistically significant $(0.095, p<0.001)$. This implies that interactions using the budget encouraged managers' organizational citizenship behavior towards individuals. Regarding the perception of controllability measured by the MIMIC model, the sensitivity of the performance scale was not significant (0.065), while accuracy exerted a negative influence $(-0.374, p<0.001)$. We discuss this result in the following section.

To test H4, we assessed the indirect effect of trust (delta method) on the interactive use of the budget and on organizational citizenship behavior. The results are shown in Table 4. We observed indirect effects of trust on in-role behavior $(0.107, p<0.001)$ and OCB-I $(0.191, p<0.001)$. For the combined effect, shown as the sum of direct effects examined in $\mathrm{H} 3 \mathrm{~b}$ and $\mathrm{H} 4$, each exhibited positive values (in-role behavior: 0.096, $p<0.001$; OCB-I: $0.286, p<0.001)$. While in-role behavior did not exert a significant direct effect on interactive use of the budget, there was a significant indirect effect via trust. As a result, H4 was partially supported.

Table 4: Indirect Effect of Interactive Use of the Budget, Trust, and Organizational Citizenship Behavior

\begin{tabular}{lccc}
\hline & Std. Estimate & Std. Err & $p$ value \\
\hline TRUST $>>$ IRB & 0.107 & 0.027 & $<0.001$ \\
TRUST $>$ > OCB-I & 0.191 & 0.022 & $<0.001$ \\
TRUST $>>$ OCB-O & 0.057 & 0.026 & 0.027 \\
\hline
\end{tabular}


H5 was partially supported. In-role behavior $(0.325, p<0.001)$ and OCB-I $(0.265, p<0.001)$ were statistically significant. In-role behavior and organizational citizenship behavior towards individuals exerted positive influences on management outcomes.

\section{DISCUSSION}

Based on our results, we answer our research questions based on the assumption that "authority and responsibility are not matched" are common to MCS in Japan. While designing MCS, top managers can control the extent to which the controllability principle is applied to encourage entrepreneurship (Simons, 2010). The following discussion of results occurs in this context.

The precision of performance measures was negatively associated with the perception of controllability and there were no significant relationships between the sensitivity of performance measures and the perception of controllability. These results are inconsistent with prior research, as discussed earlier. The relationship between the perception of controllability and organizational citizenship behavior was negative, as hypothesized (H1). Consistent with the argument of Burkert et al. (2011), this result shows that high perception of controllability can influence managers to pay attention exclusively to their own work.

Our results regarding the influence of the accuracy and sensitivity of the performance scale as measured by the MIMIC model on the perception of controllability did not align with prior studies. The current results did not reveal a significant value of sensitivity of the performance scale. We infer that sensitivity does not lead to enhancement of controllability, although one's efforts are reflected in the performance scale. Rather, this result suggests that accuracy of the performance scale is associated with lower controllability. Therefore, we suggest that a highly accurate performance scale can lead to a possible increase in uncontrollable factors for managers.

As several prior studies have pointed out, when dealing with dynamic competitive environments with lack of controllability, managers tend to use MCS actively (Bogsnes 2009; Dent, 1987; Frow et al., 2005). Consistent 
with these points, the results of $\mathrm{H} 2 \mathrm{a}$ and $\mathrm{H} 2 \mathrm{~b}$ supported that lack of controllability encourages both diagnostic and interactive use of the budget. The lack of controllability stimulates role conflict (Burkert et al., 2011) and leads to a situation in which they are unclear of their duties and subsequent courses of action. As a result of stress, managers are not likely to act as the OCB (Tanaka, 2012). Furthermore, in line with Matsuo et al. (2021), our results showed that interactive use of MCS enhance proactive behaviors. Although correlations were weak, the tests of $\mathrm{H} 2 \mathrm{a}$ and $\mathrm{H} 2 \mathrm{~b}$ showed that use of budget itself encouraged organizational citizenship behavior. Taken together, it appears that use of the budget reduces role conflict stemming from low controllability and complements identifying and facilitating organizational citizenship behavior (Burkert et al., 2017).

The tests of $\mathrm{H} 4$ and $\mathrm{H} 5$ not only indicated that low controllability encouraged interactive use of the budget, but also showed how forming shared responsibility mediated by trust encouraged behavior that actively supported others, which led to positive outcomes. This result supports previous studies that have examined the indirect effect of interactive use of MCS on performance through proactive behavior can be interpreted such that interactive control enhances employees' autonomous motivation to initiate changes in their work (Burkert et al., 2011; Matsuo et al., 2021). The correlation between interactive use of the budget and organizational citizenship behavior was not significant. However, interactive use of the budget mediates the formation of trust between employees and their superiors, and clarifies one's in-role behavior, which encourages supportive behavior among individuals. The results also reveal that in-role behavior and supportive behavior among individuals can enhance management outcomes.

\section{CONCLUSION AND LIMITATIONS}

To clarify the relationships among the perception of controllability, use of the budget, and behavior in Japan, we conducted a quantitative study using structural equation modeling. Here, we summarize the contributions of our study as derived from our analysis, and we present the limitations of our study as well as future research challenges. 
The first contribution is that the study provides empirical evidence that (low) controllability in Japan encourages use of the budget. A manager who is required to deal with internal and external risks will actively use budgetary control in an ambiguous situation vis-à-vis authority and responsibility, and will take preemptive action to achieve both individual and organizational objectives. In the field of beyond budgeting, breach of the controllability principle is recommended normatively (Bogsnes, 2009) as well as by empirical evidence from case studies (Frow et al., 2005). Shimizu (2013), who indicated that the essence of beyond budgeting is not the abolition of a budget, but rather to enhance existing management systems by implementing a forward-looking method, such as forecasting and robust thinking, to flexibly adapt to changes in the environment. The study demonstrates that a robust link between the "tool" and the "process" can effectively support business management as suggested by researchers and practitioners of beyond budgeting.

The second contribution is that the study demonstrated that interactive use of the budget, stimulated by lack of controllability, encourages altruistic behavior via trust. By budgeting interactively, not only is organizational citizenship behavior induced, but one's in-role behavior and behavior to support others is induced by communicating with trusted superiors in uncontrollable situations. This finding is consistent with Burkert et al. (2017), who showed that lack of controllability indirectly produces flexible role orientation through role conflict, and encourages proactive behavior.

The third contribution lies in our research methodology. Sharing responsibility and horizontal/vertical interaction within the organization, which characterizes the Japanese style of management accounting, has conventionally been approached via case studies to understand the associated mechanisms. Given that our study identified characteristics of the Japanese style of management accounting via quantitative analysis, it contributes to theoretical triangulation (Modell, 2005). Given that survey studies of individuals are relatively scarce in Japan (Kato et al., 2008), our Internetbased survey of managers addresses a gap in the existing literature.

The limitations of the study are as follows: The first limitation is the internal validity of the measurement scale and its question items. The MIMIC model of Burkert et al. (2011), which was selected to examine 
the perception of controllability, did not identify the factors that defined managers' perceptions of controllability. That is, the study did not demonstrate whether breach of the controllability principle was intentional via MCS, or whether it was unintentionally created by institutional/cultural factors. In amoeba management and Murata Manufacturing, shared responsibility is intentionally embedded in MCS (Maruta, 2008).

That the sensitivity and accuracy of the performance scale were not consistent with the findings of prior studies implies that other factors may reduce controllability (Burkert et al., 2011; 2017). For example, it is likely that factors that define controllability, such as other managers' behavior, superior's decision-making, and the external environment, could affect the perception of controllability (Merchant, 1989; Giraud et al., 2008). Furthermore, if increased accuracy of performance scales leads to an increase in uncontrollable factors for the manager, there is a possibility that the respondents conflated controllability with the ability to influence while responding to the questionnaire (Dearden, 1987; Merchant, 1989). There is also a possibility that the incongruence of authority and responsibility was caused by factors that were not intended by MCS design. For example, the life-long employment system unique to Japan, might have exerted an influence on controllability by valuing group-oriented order. To gain deeper understanding of the perceptions of controllability that are unique to Japan and MCS package (Malmi \& Brown, 2008), it appears that additional research is needed.

The second limitation is the reliability and validity of results, including model fit. As noted earlier, the fit of the structural equation might have been insufficient. It may be valuable to pursue a better-fitting model by excluding insignificant variables.

Future research could analyze the dynamic tension (Henri, 2006) that the diagnostic and interactive use of the control system produces. Simons (2005) also argued for the need to adjust the levers of the diagnostic control and interactive network to produce an entrepreneurial gap. Further analysis to clarify this point is highly recommended. 


\section{REFERENCES}

Abernethy, M. A., \& Brownell, P. (1999). The role of budgets in organizations facing strategic change: An exploratory study. Accounting, Organizations and Society, 24(3), 189-204.

Adachi, H. (2008). Observing responsibility Accounting through utilizing management by objectives. Keizai Ronso, 182(5-6), 590-614 (in Japanese).

Banker, R. D., \& Datar, S. M. (1989). Sensitivity, precision, and linear aggregation of signals for performance evaluation. Journal of Accounting Research, 27, 21-39.

Bedford, D. S., \& Speklé, R. F. (2018). Construct validity in survey-based management accounting and control research. Journal of Management Accounting Research, 30(2), 23-58.

Bisbe, J., \& Otley, D. (2004). The effects of the interactive use of management control systems on product innovation. Accounting, Organizations and Society, 29(8), 709-737.

Bogsnes, B. (2009). Implementing beyond budgeting: Unlocking the performance potential. John, Wiley and Sons, Hoboken, NJ.

Burkert, M., Fischer, F. M., \& Schäffer, U. (2011). Application of the controllability principle and managerial performance: The role of role perceptions. Management Accounting Research, 22(3), 143-159.

Burkert, M., Fischer, F. M., Hoos, F., \& Schuhmacher, K. (2017). The relationship between lack of controllability and proactive work behaviour: An empirical analysis of competing theoretical explanations. Accounting and Business Research, 47(2), 144-171.

Bushman, R. M., Indjejikian, R. J., \& Smith, A. (1995). Aggregate performance measures in business unit manager compensation: The role of intrafirm interdependencies. Journal of Accounting Research, $33,101-128$. 
Cheng, M. M., \& Coyte, R. (2014). The effects of incentive subjectivity and strategy communication on knowledge-sharing and extra-role behaviours. Management Accounting Research, 25(2), 119-130.

Chong, K. M., \& Mahama, H. (2014). The impact of interactive and diagnostic uses of budgets on team effectiveness. Management Accounting Research, 25(3), 206-222.

Dearden, J. (1987). Measuring profit center managers. Harvard Business Review, 65(5), 84-88.

Demski, J. S. (1994). Managerial uses of accounting information. Kluwer Academic Publishers, Norwell, Boston, MA.

Dent, J. F. (1987). Tensions in the design of formal control systems: A field study in a computer company. In W. J. Burns Jr. \& R. S. Kaplan (Eds.), Accounting and management. Harvard Business School Press, Boston, MA, 119-145.

Drury, C., El-Shishini, H., \& CIMA Accountants. (2005). Divisional performance measurement: An examination of the potential explanatory factors: Chartered Institute of Management Accountants.

Eatough, E. M., Chang, C. H., Miloslavic, S. A., \& Johnson, R. E. (2011). Relationships of role stressors with organizational citizenship behavior: a meta-analysis. Journal of Applied Psychology, 96(3), 619-632.

Fremgen, J. M., \& Liao, S. S. (1981). The allocation of corporate indirect costs. Institute of Management Accountants.

Frow, N., Marginson, D., \& Ogden, S. (2005). Encouraging strategic behaviour while maintaining management control: Multi-functional project teams, budgets, and the negotiation of shared accountabilities in contemporary enterprises. Management Accounting Research, 16(3), 269-292.

Giraud, F., Langevin, P., \& Mendoza, C. (2008). Justice as a rationale for the controllability principle: A study of managers' opinions. Management Accounting Research, 19(1), 32-44. 
Henri, J-F. (2006). Organizational culture and performance measurement systems. Accounting, Organizations and Society, 31(1), 77-103.

Henttu-Aho, T. (2018). The role of rolling forecasting in budgetary control systems: Reactive and proactive types of planning. Journal of Management Control, 29(3), 327-360.

Horngren, C. T. (1967). Cost accounting: A managerial emphasis (2nd ed.). Prentice-Hall, Englewood Cliffs, NJ.

Kato, Y., Ohura, K., \& Arai, K. (2008). Features and challenges of survey management accounting research in Japan. Kanri-kaikei gaku, 16(1), 3-18 (in Japanese).

Lau, C. M., \& Tan, S. L. C. (2012). Budget targets as performance measures: The mediating role of participation and procedural fairness. In M. J. Epstein \& J. Y. Lee (Eds.), Advances in management accounting, 20, Emerald Publishing, Bingley, England, 151-185.

Mahoney, T. A., Jerdee, T. H., \& Carroll, S. J. (1963). Development of managerial performance: A research approach. South-Western Publishing, Cincinnati, $\mathrm{OH}$.

Mahoney, T. A., Jerdee, T. H., \& Carroll, S. J. (1965). The job(s) of management. Industrial Relation, 4, 97-110.

Malina, M. A., \& Selto, F. H. (2001). Communicating and controlling strategy: An empirical study of the effectiveness of the balanced scorecard. Journal of Management Accounting Research, 13, 47-90.

Malmi, T., \& Brown, D. A. (2008). Management control systems as a package-Opportunities, challenges and research directions. Management Accounting Research, 19(4), 287-300.

Marginson, D., \& Ogden, S. (2005). Managers, budgets and organisational change: Unbundling some of the paradoxes. Journal of Accounting and Organizational Change, 1(1), 45-61. 
Maruta, O. (2008). A consideration of the concept of profit in management accounting. In Fujita, M. (Ed), A topology in accounting earnings. Doubunkann, Tokyo, 169-187 (in Japanese).

Maruta, O. (2010). A consideration of responsibility accounting in Kyosera Amoeba Management System. Melco Journal of Management Accounting Research, 3(1), 27-37 (in Japanese).

Matsuo, M., Matsuo, T., \& Arai, K. (2021). The influence of an interactive use of management control on individual performance: Mediating roles of psychological empowerment and proactive behavior. Journal of Accounting \& Organizational Change, 17(2), 263-281.

Merchant, K. A. (1989). Rewarding results: Motivating profit center managers: Harvard Business School Press, Boston, MA.

Modell, S. (2005). Triangulation between case study and survey methods in management accounting research: An assessment of validity implications. Management Accounting Research, 16(2), 231-254.

Moers, F. (2006). Performance measure properties and delegation. The Accounting Review, 81(4), 897-924.

Moon, P., \& Fitzgerald, L. (1996). Delivering the goods at TNT: The role of the performance measurement system. Management Accounting Research, 7(4), 431-457.

Organ, D., Podsakoff, P. M., \& MacKenzie, S. B. (2006). Organizational citizenship behavior: Its nature, antecedents, and consequences. Sage Publications, Thousand Oaks, CA.

Otley, D. (1990). Issues in accountability and control: Some observations from a study of colliery accountability in the British Coal Corporation. Management Accounting Research, 1(2), 101-123.

Oura, K. (2006). Control system and trust in inter-organizations. Genkakeisan Kenkyu, 30(2), 63-71 (in Japanese). 
Podsakoff, N. P., Whiting, S. W., Podsakoff, P. M., \& Blume, B. D. (2009). Individual- and organizational-level consequences of organizational citizenship behaviors: A meta-analysis. Journal of Applied Psychology, 94, 122-141.

Podsakoff, P. M., MacKenzie, S. B., \& Hui, C. (1993). Organizational citizenship behaviors and managerial evaluations of employee performance: A review and suggestions for future research. In Rowland, K. M. (ed.) Research in personnel and human resources management, 11, JAI Press, Greenwich, CT, 1-40.

Read, W. H. (1962). Upward communication in industrial hierarchies. Human Relations, 15, 3-15.

Rowe, C., Birnberg, J. G., \& Shields, M. D. (2008). Effects of organizational process change on responsibility accounting and managers' revelations of private knowledge. Accounting, Organizations and Society, 33(2-3), 164-198.

Shimizu, T. (2013). Performance management in strategy execution. Chuo Keizai Sha, Tokyo (in Japanese).

Simons, R. (2005). Levers of organization design: How managers use accountability systems for greater performance and commitment. Harvard School Press, Boston, MA.

Simons, R. (2010). Seven strategy questions: A simple approach for better execution. Harvard Business School Press, Boston, MA.

Simons, R., \& Dávila, A. (2021). How top managers use the entrepreneurial gap to drive strategic change. European Accounting Review, 30(4), 583-609.

Solomons, D. (1965). Divisional performance: Measurement and control: Markus Wiener Publishers, New York, NY.

Su, S. X., Baird, K., \& Nuhu, N. (2021). Controllability of performance measures and managerial performance: The mediating role of fairness. 
Meditari Accountancy Research, ahead-of-print. https://doi.org/10.1108/ MEDAR-07-2020-0957.

Tanaka, K. (2012). Organizational citizenship behavior in Japanese workplace. Nippon Roudou Kenkyu Zasshi, 54(10), 14-21 (in Japanese).

Vancil, R. F. (1979). Decentralization: Managerial ambiguity by design. Dow Jones-Irwin, Homewood, IL.

Welsch, G. A. (1957). Budgeting: Profit-planning and control. PrenticeHall, Englewood Cliffs, NJ.

Williams, L. J., \& Anderson, S. E. (1991). Job satisfaction and organizational commitment as predictors of organizational citizenship and in-role behaviors. Journal of Management, 17(3), 601-617.

Yamagishi, T. (1998). The structure of trust: An evolution game in mind and social. Tokyo-daigaku Shuppan kai, Tokyo (in Japanese).

Yokota, E. (1998). Management and psychology in flat organization: Management control in turbulent Era. Keio-Gijuku daigaku Shuppan kai, Tokyo (in Japanese). 